\title{
Numerical studies of geomagnetically induced electric field on seafloor and near coastal zones incorporated with heterogeneous conductivity distributions
}

Tada-nori Goto ${ }^{1,2}$

\begin{abstract}
Abrupt changes of geomagnetic field can make large induced electric field and resultant electric current on the earth, which is called as geomagnetically induced current (GIC). It can yield damages to pipelines, cables, and other architectures. For understanding the phenomena and future risks of $\mathrm{GlC}$, it is necessary to evaluate how the sub-surface electrical conductivity structure is important for the GIC because the heterogeneous conductivity structure in the crust and mantle affects the induced electrical current locally. The hazard prediction based on the homogeneous earth may result in the underestimation. Here, I introduce possible cases of geomagnetically induced electric field (GIE) on seafloor and near coastal areas, based on numerical forward simulations on one-, two-, and three-dimensional (1-D, 2-D, and 3-D) earth's structure including the sea layer. On the 1-D case, I show the possible amplitude of GIE on the seafloor, far from the coastal area. The second case study comes from 2-D forward simulation, in which the straightly elongated coastal line is assumed, and various sub-surface and sub-seafloor conductivity structures are imposed. The numerical results suggest that the amplitude of GIE on land becomes more than two times larger than that of the homogeneous earth without the sea layer. The width of land zone with larger GIE is about $20 \mathrm{~km}$ from the coast. In forward modeling with a simplified 3-D bathymetry, land electric field near the bay area increases with about ten times larger than that of the inland one. The seafloor GIE near the peninsula area also indicates about four times larger value than that of the other area at the same water depth. These phenomena can be explained by the boundary charge along the coastal area. I conclude that 3-D earth's conductivity structure including the realistic bathymetry and sub-surface and sub-seafloor structures should be essential and focused for the hazard assessment of GIC.
\end{abstract}

Keywords: GIC, Conductivity structure, Seafloor, Coastal effect

\section{Introduction}

Geomagnetic storms are potentially hazardous to human society. The electric field in the earth, induced by the geomagnetic storms, generates the large unpredictable electric current in conductors on the earth's surface. This is so-called geomagnetically induced current (GIC), which can yield damages to pipelines, railways, cables, and other architectures which have long electrical conductor systems. For example, the end-to-end voltages

\footnotetext{
Correspondence: goto.tadanori.8a@kyoto-u.ac.jp

${ }^{1}$ Graduate School of Engineering, Kyoto University, C1-2-216, Kyodai-Katsura, Nishikyo, Kyoto 615-8540, Japan

${ }^{2}$ Japan Agency for Marine-Earth Science and Technology 2-15, Natsushima, Yokosuka, Kanagawa 237-0061, Japan
}

\section{Springer}

associated with GIC can be very large along power lines and trans-oceanic submarine communication cables. Buried pipelines may suffer from serious corrosion of the steel due to GIC.

One of the famous damages is emerged on the HydroQuébec power system during the great magnetic storm on March 13, 1989. Bolduc (2002) reported that the electrical power supply was interrupted for many hours, and voltage instability which resulted in safety features tripping the transmission system costs $6.5 \mathrm{M} \$$ in material damages alone. In his report, the system collapse followed a sudden large variation of geomagnetic field (e.g., about $1000 \mathrm{nT}$ decrease in the north component within several minutes). The large GIC made the system 
unstable since a number of static compensators, essential for maintaining dynamic stability, started tripping one after the other. Another example of GIC is recorded in the southern Finland (Pirjola 2005; Pirjola 2012). The maximum current through a transformer neutral in the power grid was about $200 \mathrm{~A}$ at the geomagnetic variation (about $2000 \mathrm{nT}$ within several minutes).

For understanding the phenomena and future risks of GIC, many efforts have been done. Although the number of directly observed data of GIC at the power grid (e.g., Watari 2015) is limited, the recent numerical studies try to cover the lack of observation and to attempt to assess the GIC. Thomson et al. (2009) introduced progress toward integrated European scale models of geomagnetic and geoelectric fields for modeling GIC in power grids and pipelines. Pulkkinen et al. (2010) presented a model for computing GIC from local geomagnetic field observations carried out in Hokkaido, Japan. The model composed of a layered sub-surface structure reproduced the observed GIC with a very good accuracy. Wei et al. (2013) interpolated sparsely distributed magnetometer data and predicted the surface electric field across North America at the geomagnetic storms in 1989 and 2003. Their estimation based on the layered regional earth models indicates good agreement between the measured and interpolated data. They also found that the induced electric field strongly depends on the local surface impedance, resulting in surprisingly strong electric field amplitudes along the Atlantic and Gulf Coast. Boteler (2014) focused the 1989 magnetic disturbance at Québec, estimated the electric field based on the layered earth model, and showed how uncertainty in the earth model influences the calculation. Püthe et al. (2014) calculated electric field on a layered earth model incorporated with 3-D surface conductance distributions, which was compared with observed ones.

The many model studies have been done; however, most of them are based on the layered earth model (without horizontal heterogeneity) and have not handled the spatial heterogeneity of earth's conductivity structure. It is necessary to discuss how large impacts the heterogeneity has on the GIC estimation because the heterogeneous conductivity structure in the crust and mantle affects the induced electrical current locally. Lack of the view may result in underestimation of the GIC hazard. Since the highly populated cities are concentrated along the coasts, the conductivity contrast between land and ocean should be discussed quantitatively for the GIC predictions. Moreover, a few studies have been reported about the GIC on the seafloor and near the coastal areas. Similar to land, the long electrical conductor systems such as submarine cables and pipelines are installed on the seafloor and coastal area.
In this study, I introduce possible cases of geomagnetically induced electric field (GIE), on seafloor and near coastal areas, which yields the GIC, based on numerical forward simulations on one-, two-, and three-dimensional (1-D, 2-D, and 3-D) earth's structure including the sea layer. Through the 1-D calculations, I will discuss how large GIE is expected on the seafloor. Although the similar evaluations on the seafloor with 1-D earth models has been published (Pirjola et al. 2000; Pirjola 2002; Boteler and Pirjola 2003), the more realistic sub-seafloor structure is adopted in this study. Then, the 2-D and 3-D calculations help us to understand the coastal effect on GIE, which will enhance the electric field near the ocean. Note that this paper is focused on the discussion of horizontal geoelectric field at the Earth's surface. For computation of GIC in the power grid, etc., produced by the geoelectric field, other engineering investigations such as in Pirjola (2012) are required.

\section{Methods}

I employed theoretical and numerical methods for electric field calculations on 1-D, 2-D, and 3-D earth's conductivity structures. In this study, the spatially homogeneous electric current in the magnetosphere or ionosphere is assumed to be a source of GIE. The primary magnetic field (directly generated from the source current) is common on the surface and has the horizontal components only. It is an assumption for the magnetotelluric sounding (e.g., Kaufman and Keller 1981) but will be not appropriate because of the heterogeneous pattern of source electric current of GIE as shown in Thomson et al. (2009; see Fig. 3 in their article). For example, as reviewed in Mareschal (1986), the induced electric field directly observed under the electrojet tends to be underestimated at long periods while the reverse (overestimation of the induced electric field) is true past the edges of the electrojet. Although the source heterogeneity should be dealt in the future work, the simple assumption can be applied at the mid latitude area far from the electrojet and also can be worth as a practical method to evaluate the averaged GIE at the highlatitude area.

The 1-D calculation is based on the theoretical study of magnetotelluric sounding method (e.g., Kaufman and Keller, 1981). The magnetotelluric impedance $Z(f)$ at a frequency $(f)$ can be defined as a function of amplitude of horizontal electric field at an observation site $\left(E_{x}(f)\right)$ and horizontal magnetic disturbance at the same site with the same frequency $\left(H_{y}(f)\right)$ as follows;

$$
Z(f)=\frac{E_{x}(f)}{H_{y}(f)}=\frac{E_{x}(f)}{\mu^{-1} B_{y}(f)}
$$

where $B_{y}(f)$ is the magnetic flux density and $\mu$ is the magnetic permeability $\left(4 \pi \cdot 10^{-7} \mathrm{H} / \mathrm{m}\right.$, assumed to be 
uniform in the air and ground). If the earth has a uniform electrical conductivity $(\sigma)$, the impedance can be written as the following equation based on the frequency-domain Maxwell's equations (e.g., Kaufman and Keller 1981);

$$
Z(f)=\frac{\omega \mu}{k}, \text { where } k=\sqrt{i \sigma \omega \mu}
$$

where $\omega$ and $i$ are the angular frequency $(\omega=2 \pi f)$ and the imaginary unit, respectively. In the 1-D case, the impedance at top of each layer $j=1$ (surface), 2(sub-surface), ..., $N$ (the deepest layer) can be theoretically derived as follows (Kaufman and Keller 1981);

$$
\begin{aligned}
& Z_{j}(f)=\frac{\omega \mu}{k_{j}} \frac{1-R_{j} e^{2 i k_{j} h_{j}}}{1+R_{j} e^{2 i k_{j} h_{j}}}, \text { where } k_{j}=\sqrt{i \sigma_{j} \omega \mu} \\
& R_{j}=\frac{\omega \mu / Z_{j+1}(f)-k_{j}}{\omega \mu / Z_{j+1}(f)+k_{j}}
\end{aligned}
$$

The parameters $\sigma_{j}$ and $h_{j}$ are the conductivity and thickness of layer $j$, respectively. Since the impedance at the top of the deepest layer can be simply derived as $Z_{N}(f)=\omega \mu / k_{N}$, we can estimate $Z_{N-1}(f), Z_{N-2}(f), \ldots$ $Z_{2}(f), Z_{1}(f)$, recursively.

The 1-D magnetotelluric theory also gives us the quantitative estimation of GIE on the seafloor. From Eq. 1, it can be written as

$$
E_{x}(f)_{\text {seafloor }}=\mu Z_{s}(f) \frac{B_{y}(f)_{\text {seafloor }}}{B_{y}(f)_{\text {surface }}} B_{y}(f)_{\text {surface }}
$$

where $Z_{s}(f)$ is the impedance on the seafloor. Now, we can normalize the amplitude of magnetic field at the sea surface (i.e., $B_{y}(f)_{\text {surface }}=1 \mathrm{nT}$ ). The attenuation ratio of magnetic field in the seawater layer, $B_{y}(f)_{\text {seafloor }} / B_{y}(f)_{\text {surface, }}$ can be described theoretically as follows (Kaufman and Keller 1981);

$$
\begin{aligned}
& \frac{B_{y}(f)_{\text {seafloor }}}{B_{y}(f)_{\text {surface }}}=\frac{1+R_{s}}{1+R_{s} e^{2 i k_{s} h_{s}}} e^{i k_{s} h_{s}}, \\
& \text { where } k_{s}=\sqrt{i \sigma_{s} \omega \mu} \\
& R_{s}=\frac{\omega \mu / Z_{s}(f)-k_{s}}{\omega \mu / Z_{s}(f)+k_{s}}
\end{aligned}
$$

where $\sigma_{s}$ and $h_{s}$ are the conductivity and thickness of seawater layer. The seafloor impedance $Z_{s}(f)$ can be estimated from Eqs. 3 and 4; therefore, the Eq. 7 can be solved and used for the prediction of GIE on seafloor.

For demonstration how the sub-seafloor structure affects the seafloor GIE, two different types of 1-D subseafloor conductivity structures are assumed here (summarized in Table 1). The former one is a layered structure below the Pacific plate (PAC), representing the old oceanic plate. The latter one is for the Philippine Sea plate (PHS),
Table 1 Two contrastive models of sub-seafloor 1-D conductivity structures. The seawater conductivity is assumed as $4 \mathrm{~S} / \mathrm{m}$

\begin{tabular}{lll}
\hline & $\begin{array}{l}\text { Pacific plate (PAC) } \\
\text { model }\end{array}$ & $\begin{array}{l}\text { Philippine Sea plate } \\
\text { (PHS) model }\end{array}$ \\
\hline Crust & $0.01 \mathrm{~S} / \mathrm{m}$ & $0.01 \mathrm{~S} / \mathrm{m}$ \\
& Depth 0-10 km bsf. & Depth 0-10 km bsf. \\
Upper most mantle & $0.001 \mathrm{~S} / \mathrm{m}$ & $0.001 \mathrm{~S} / \mathrm{m}$ \\
& Depth $10-150 \mathrm{~km}$ bsf. & Depth $10-40 \mathrm{~km}$ bsf. \\
Upper mantle & $0.033 \mathrm{~S} / \mathrm{m}$ & $0.033 \mathrm{~S} / \mathrm{m}$ \\
& Depth $>150 \mathrm{~km}$ bsf. & Depth $>40 \mathrm{~km}$ bsf.
\end{tabular}

bsf below the seafloor

representing the young oceanic plate. Both are simplified from the 1-D models obtained by the seafloor magnetotelluric observations (Baba et al. 2010). The uppermost mantle is relatively less conductive than the crust and upper mantle (Table 1). The conductivity of mantle increases toward the depth due to the temperature rise, and the crust also indicates high conductivity due to inclusion of water. Note that the PHS indicates more conductive feature (e.g., thinner upper most mantle in Table 1) than PAC. As in Baba et al. (2010), it can be interpreted as the existence of partially molten in the PHS mantle while the partial melting is not required below the PAC, if the conductivity is interpreted simply as the effect of temperature. In addition to the sub-seafloor structure, a seawater layer is added to the top of each model in Table 1 with various water depths: 1000,4000 , and $0 \mathrm{~m}$ (i.e., no seawater case). As a result, six different GIEs are estimated as shown in Fig. 1.

Note that the GIE in this study is estimated in the frequency domain, not in the time domain. Although most of the GIC studies are based on the analysis of time

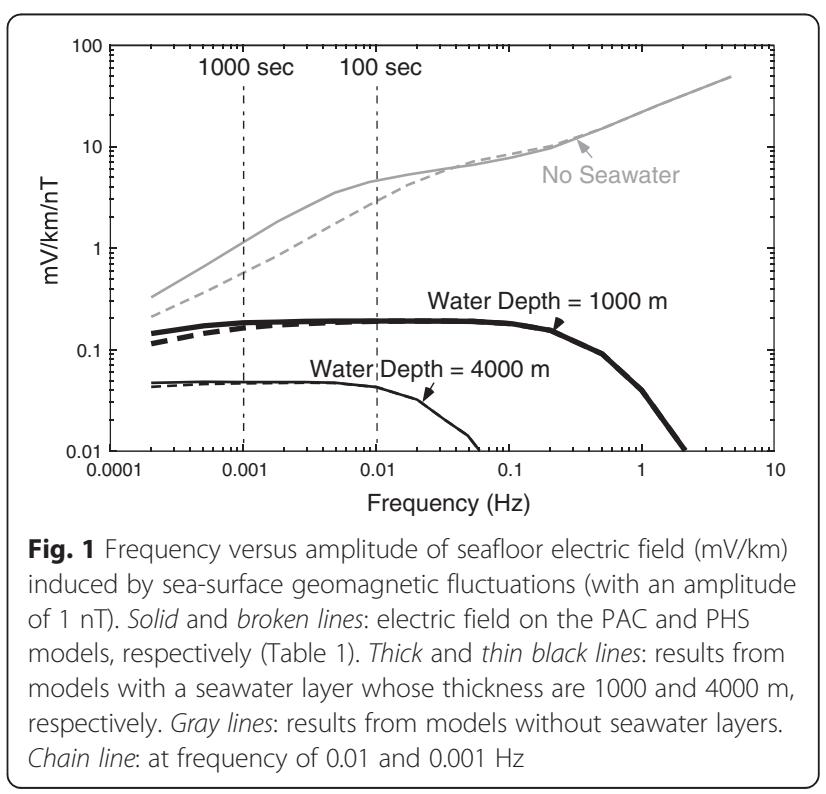


series data, the GIE due to magnetic fluctuations can be written in the frequency domain such as in Eq. 5. Therefore, for the fundamental studies of GIE, it is described as a function of frequency in this study. The transform of the frequency-domain GIE to the time domain is easily achieved; the frequency-domain GIE per unit amplitude of magnetic fluctuation (as shown in Fig. 1), and the spectrum of observed magnetic field can give us the predicted spectrum of GIE. Inverse Fourier transform of the GIE spectrum will yield the time series of predicted GIE. In the following 2-D and 3-D calculations, the frequency-domain approach is also adopted.

The 2-D model can include both land and ocean with a straight coastline and is useful for demonstrating the coastal effect on GIE. The numerical calculation is based on the finite element method (FEM) developed by Uchida and Ogawa (1993), which follows the method described in Rodi (1976). The 2-D model has an elongated structure in which the conductivity can vary across the strike and to the depth. It consists of aggregation of small rectangular blocks having the own conductivity values. The induced electric field on land and seafloor are obtained by the calculation, assuming the unit amplitude of magnetic field on the sea/land surface.

As well known, the two modes of electromagnetic inductions are available for 2-D cases: the transverse magnetic (TM) mode and the transverse electric (TE) mode (e.g., page 37 in Chave and Jones 2012). In the TM mode, the magnetic field points in the strike of 2-D structure and the electric field lies in the plane orthogonal to strike. The TE mode has the complementary set, with electric field in the strike direction and the magnetic field orthogonal to the strike. In this study, I focus the TM mode induction for evaluation of the coastal effect on GIE. As typically shown in Vozoff (1972), the apparent resistivity at a frequency rapidly changes at a vertical contact of conductivity heterogeneity, similar to coastline. Since the amplitude of magnetic field is common at the earth's surface in the TM mode theoretically, the rapid change means less-continuous electrical field across the vertical contact. On the contrary, in the TE mode, the apparent resistivity gradually changes across the vertical contact. It means that the TE-mode electrical field can be approximately inferred by interpolation of calculated results on the 1-D models. Therefore, the GIE estimation in the TM mode is more meaningful for the 2-D studies.

The 2-D model used in this study is based on the land and seafloor magnetotelluric observations across the coastline of the Kii peninsula, Japan (Kasaya et al. 2005). A simplified conductivity model is created (see later, in Fig. 2d) and is modified to other three models for sensitivity check of GIE to the sub-surface conductivity structures. All four 2-D models having a conductive sea layer $(4 \mathrm{~S} / \mathrm{m})$ are used for the discussion (Fig. 2). The induced electric field is calculated on the land surface and seafloor at various frequencies from 0.01 to $0.001 \mathrm{~Hz}$.

The numerical calculation of induced electric field on the 3-D earth's structure is carried out by using the finite difference method developed by Mackie et al. (1994). The purpose of 3-D modeling is for the discussion on how the complicated bathymetry affects the GIE on the seafloor. Similar to the 2-D model, the 3-D model consists of a number of conductivity blocks with cuboids. For focusing the bathymetric effect only, the sub-surface and subseafloor conductivity are assumed to be uniform with conductivity of $0.01 \mathrm{~S} / \mathrm{m}$ (as shown in Figs. 3 and 4). The seawater conductivity is fixed as $4 \mathrm{~S} / \mathrm{m}$. The bathymetric data off the Tokai area (off the Omaezaki peninsula, Japan) is simplified and imposed to the 3-D model. Two orthogonal horizontal magnetic fields ( $\mathrm{x}$ and $\mathrm{y}$ directions) are respectively added as source of induction, at the height of $100 \mathrm{~km}$ above the surface of 3-D model. The frequency of source used here is $0.001 \mathrm{~Hz}$.

\section{Results and discussion}

As a result of the 1-D modeling studies (Fig. 1), the seafloor electric field cannot be negligible at shallow water and low frequency cases. In the case of water depth of $1000 \mathrm{~m}$, the amplitude of electric field is relatively smaller than that of the land case (no seawater) but is still $15-30 \%$ of the land case at the frequency of $0.001 \mathrm{~Hz}$. It will be larger level if the water depth is less than $1000 \mathrm{~m}$. On the contrary, in the deeper water case (e.g., $4000 \mathrm{~m}$ ), the amplitude of electric field goes down less than $8 \%$ of the land value. Such a small electric field is similar to the previous studies (Pirjola et al. 2000; Boteler and Pirjola 2003).

The quantitative estimation of seafloor electric field helps the discussion on how large voltages can be excited along the seafloor infrastructures. For example, an extreme magnetic storm in 1859, called as the Carrington event, brought the large geomagnetic change of about $1600 \mathrm{nT}$ at Bombay, India (Tsurutani et al. 2003). They reported the continuous decrease of magnetic field during several thousand seconds. If surface geomagnetic fluctuations have the amplitude of $1600 \mathrm{nT}$ and the frequency of $0.001 \mathrm{~Hz}$, and a submarine cable or pipeline with length of $2000 \mathrm{~km}$ is installed on the seafloor with water depth of $1000 \mathrm{~m}$, we can predict the end-to-end voltages along the infrastructure. By multiplying the electric field at $0.001 \mathrm{~Hz}$ in Fig. $1(0.16-0.19 \mathrm{mV} / \mathrm{km} / \mathrm{nT})$, amplitude of magnetic field and the cable length, the voltages can be predicted as about $500-600 \mathrm{~V}$. It is obvious that the shallower water environment increases the possibility of hazard on seafloor infrastructures. On the other hand, the seafloor GIE would be less hazardous at a higher frequency than $0.01 \mathrm{~Hz}$ in the case of water depth of $4000 \mathrm{~m}$ (Fig. 1), although the land case indicates the 

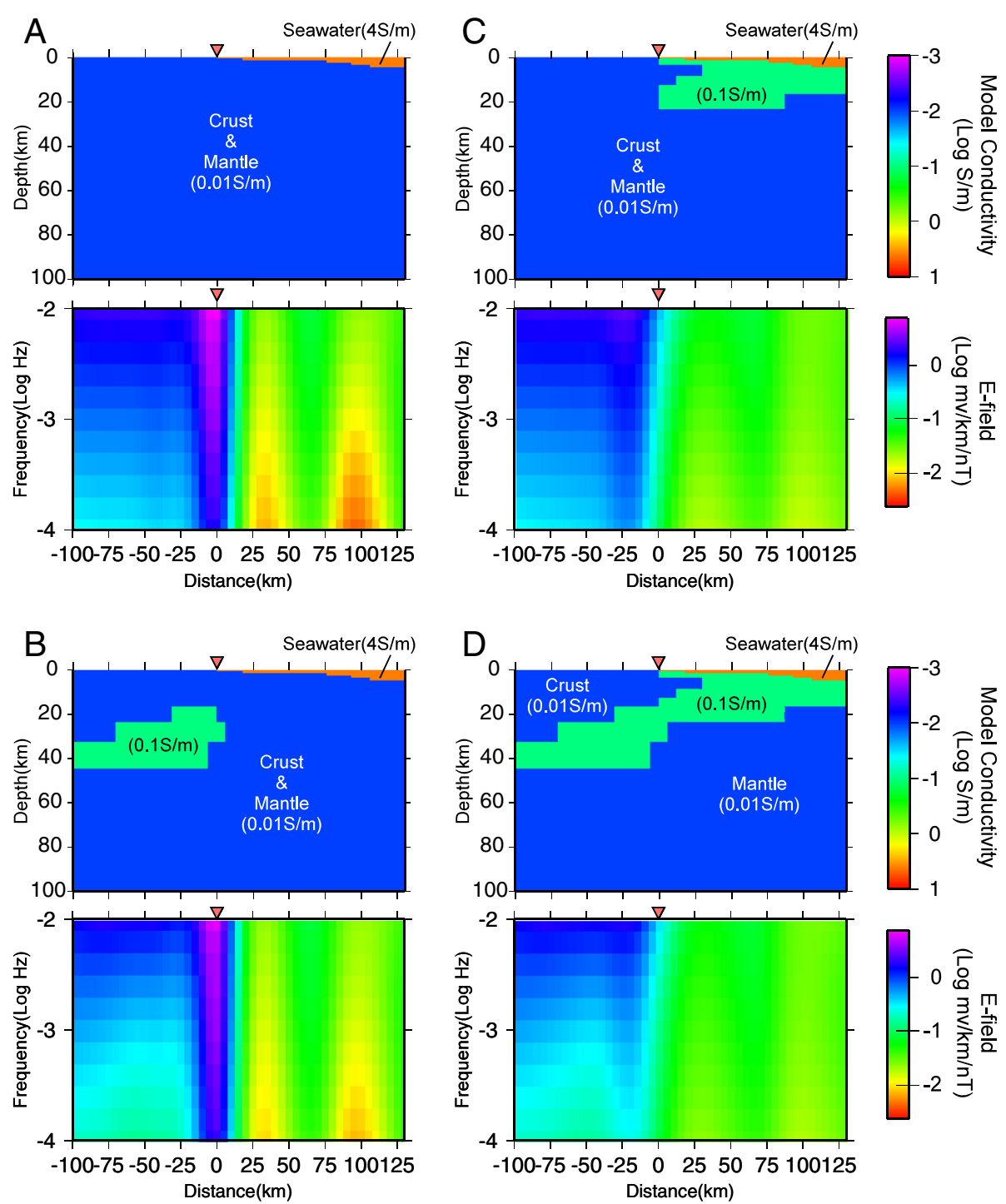

Fig. 2 Cross sections of four 2-D land-ocean conductivity models, together with induced electric field of TM mode on land surface and on seafloor. A seawater layer is commonly added to the shallow-right side of each model $(4 \mathrm{~S} / \mathrm{m})$. The coastline, shown as an inverted triangle in each model, is located at the distance of $0 \mathrm{~km}$. a Homogeneous underground model. The conductivity values for crust and mantle are assumed as $0.01 \mathrm{~S} / \mathrm{m}$ based on Kasaya et al. (2005). b Land-side conductive model. The deep portion of land has a conductive feature. The conductivity and shape comes from the subducting oceanic plate shown in the model D. c Ocean-side conductive model. Similar to the model B, but the sub-seafloor structure has the conductive feature. $\mathbf{d}$ Subduction model. The subducting oceanic plate (PHS) is added whose top layer has a high conductivity $(0.1 \mathrm{~S} / \mathrm{m})$. The value and shape is based on Kasaya et al. (2005). Note that both the model conductivity and electric field are shown as logarithmic values

gradual increase at higher frequency. It is due to the shield effect by conductive seawater. In the case of water depth of $1000 \mathrm{~m}$, the shield effect becomes weak and the cut-off frequency is shifted to about $0.1 \mathrm{~Hz}$.

The 2-D modeling indicates the amplification of induced electric field is obvious in the coastal zone. Figure 2 indicates the results from four different models. The homogeneous underground model (Fig. 2a) and the landside conductive model (Fig. 2b) commonly indicate the large induced electric field in the TM mode. For example, at a frequency of about $0.01 \mathrm{~Hz}$ on model A (Fig. 2), the averaged GIE at the area between the coast line to the $20 \mathrm{~km}$ inland is about $4.7 \mathrm{mV} / \mathrm{km} / \mathrm{nT}$, more than twice of inland GIE (about $2.1 \mathrm{mV} / \mathrm{km} / \mathrm{nT}$ ). In the other models and other frequencies, the amplification of GIE near the coast can be greater; e.g., about five times at 0.01$0.001 \mathrm{~Hz}$ on the model B (Fig. 2). Therefore, the horizontal heterogeneity should be considered for the GIE estimation.

The amplification along the coast is explained by the boundary charge at the coastline (e.g., Wannamaker et al. 1984); the TM mode electric field is normal to the 

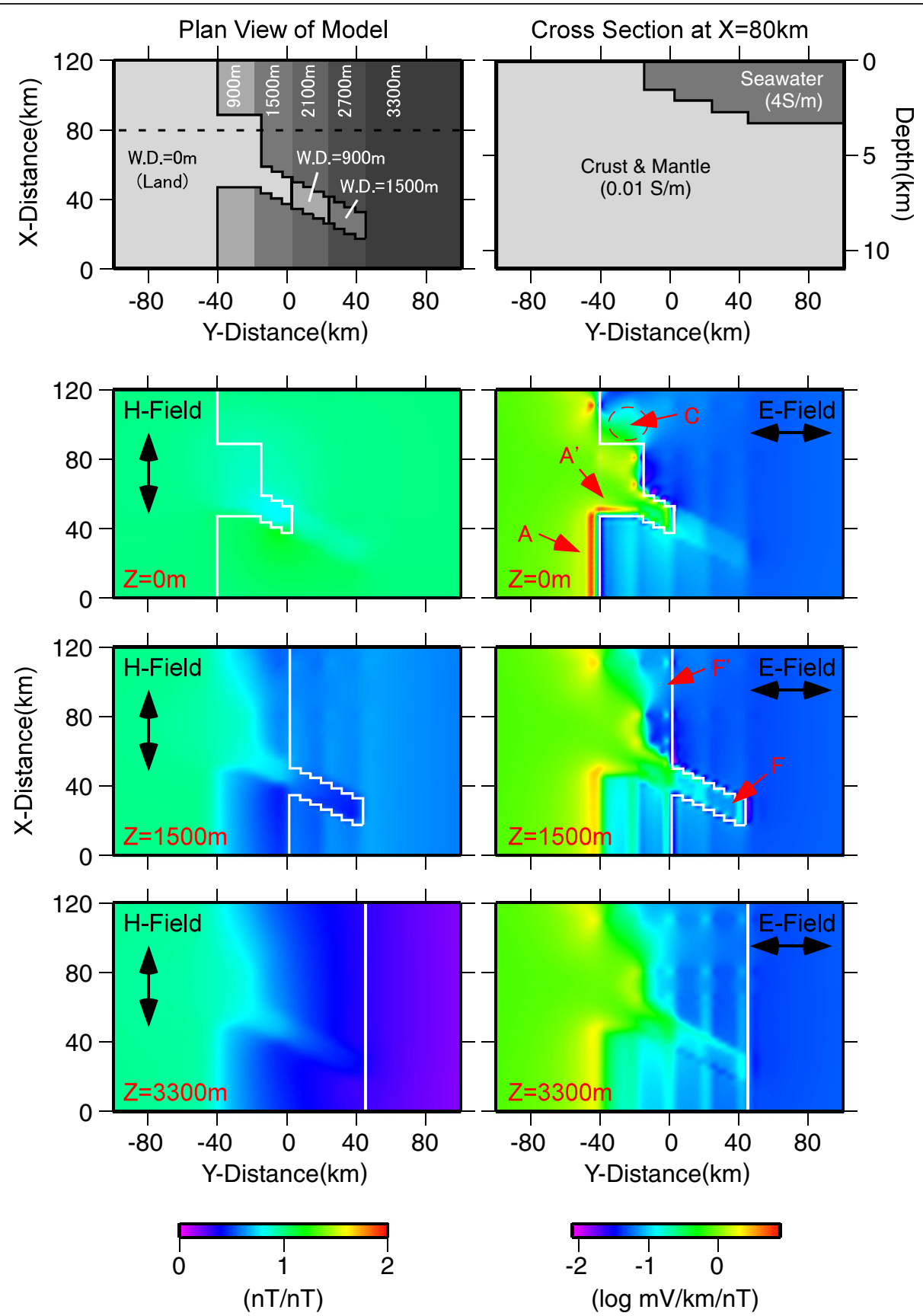

Fig. 3 Top: plane view and cross section of the 3-D conductivity model. Others: plane view of total amplitude of magnetic field (three contour maps at the left) and electric field (three at the right) at a frequency of $0.001 \mathrm{~Hz}$. Double arrows indicate the polarization of source magnetic field and the induced electric field far from the coastline. Three horizontal planes (0, 1500, and $3300 \mathrm{~m}$ depth, respectively) of magnetic and electric fields are shown, which are normalized by the amplitude of source magnetic field. White lines indicate the boundary between seawater and ground at each depth. WD water depth

vertical resistivity contacts in the earth. The continuity of electric current through the resistivity contacts can yield the discontinuity of electric field, and the resultant boundary charge will be induced at the resistivity contacts as sources for secondary electric field, which amplify the land electric field. Note that the large GIE zones spread offshore in Fig. 2a, b. It is due to the gradual change of bathymetry; the sea water layer becomes thick toward the offshore. The shallow water zones do not always contribute to the low frequency induction, so that the "coastline" at the low frequency is possibly shifted offshore. 

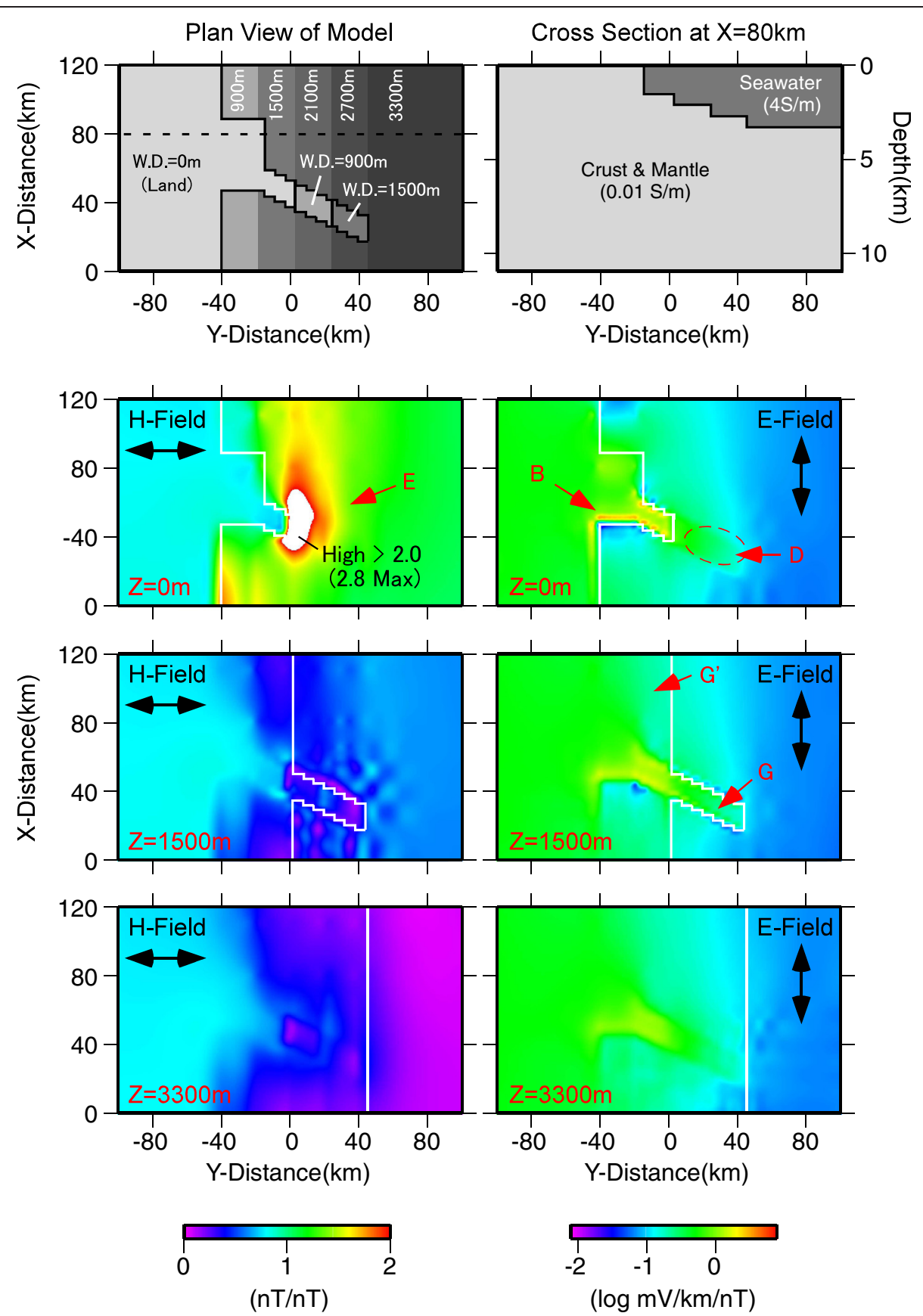

Fig. 4 Similar to Fig. 3, but the complementary set: the source magnetic field is orthogonal to the case in Fig. 3

The coastal effect yields not only amplification of electric field on land but also attenuation of seafloor electric field at some areas. In Fig. 2a, b, two zones with small GIE are revealed at a distance around +30 and $+100 \mathrm{~km}$, respectively. The former is located near the coastline, and the latter is found around the steep dipping of seafloor slope. It is also due to the boundary charge in the TM mode induction, which will be sources for secondary electric field attenuating the seafloor electric field.
The coastal effect of GIE is strongly affected by the shallow conductivity structure as shown in Fig. 2. The low conductive seafloor and high conductive seawater are directly attached each other in Fig. 2a, b. On the contrary, the crustal conductivity is varied gradually across the coastline in Fig. 2c, d. The latter models reduce the coastal effect in the TM mode (the amplification and attenuation of electric field which has been described above). 
The deeper conductivity structure does not indicate the large coastal effect at the higher frequency but affects at the lower frequency. Based on the comparison between Fig. 2a and Fig. 2b, the GIE are almost common at the frequency higher than $0.001 \mathrm{~Hz}$. However, differences are obvious at the lower frequency. If the electric field that drives GIC has large amplitude at such low frequencies, the mantle structure below the land should be considered.

The 3-D numerical modeling with a simple sub-surface structure (uniform conductivity of $0.01 \mathrm{~S} / \mathrm{m}$ ) demonstrates concentrations of electric current at the bay and peninsula areas. Figure 3 indicates the spatial distribution of electric field on and in the earth, together with the magnetic field at a frequency of $0.001 \mathrm{~Hz}$. It is obvious that the electrical field is greatly amplified near the coastline (A in Fig. 3). This coastal effect is similar as in the 2-D modeling. The area $\mathrm{A}^{\prime}$ in Fig. 3 also indicates the large electric field near the coastline. It could be explained by the electric current avoiding the peninsula and seafloor high area (i.e., spur). The bay-like area has concentration of electric current, resulting in the larger electric field on land. Similarly, the different pattern of source magnetic field yields the large electric field on land near the coastline (B in Fig. 4). The amplitude is about ten times larger than that of the inland electric field, so that the coastal effects of GIE should be considered for the future hazard mitigations.

Not only the land but also the seafloor electric field is distorted by the complicated conductivity structure. In area C (Fig. 3), the offshore electric field is relatively higher (about four times) than that of the other offshore areas with the same water depth. This area is located along the coastline, where induced electric current avoiding the resistive peninsula will be concentrated. Similar offshore electric field with larger amplitude is observed at other areas such as D in Fig. 4. On this area, the geomagnetic field is also amplified largely as shown in area E (Fig. 4), which implies the current concentration in the ocean. Thus, the seafloor GIE could be increased near the shore area. The coastal ocean area is often characterized as the shallow water depth, so that the GIE could be similar amplitude to the land case (as discussed in the 1-D modeling case).

On the other hand, the small seafloor high has less effects of amplification of GIE. For example, the seafloor electric field on the spur-like structure (F in Fig. 3 and G in Fig. 4) indicates similar amplitude to the less complicated bathymetric area (F' in Fig. 3 and G' in Fig. 4). This is possibly due to the seawater upon the spur, which can play a role of "pass way" for electrical current avoiding the concentration around the resistive spurlike structure. It also might be due to the limited spatial width of spur; much wider seafloor high (and/ or shallower top depth to the sea surface) could make a larger seafloor GIE as shown in the land case (e.g., A and A' in Fig. 3)

\section{Conclusions}

For evaluation of GIE on seafloor and near coastal zones incorporated with heterogeneous conductivity distributions of the earth, I introduce possible cases of induced electric field based on theoretical and numerical forward simulations on 1-D, 2-D, and 3-D earth's structure. On the 1-D case, the seafloor GIE is less hazardous at the higher frequency (Fig. 1; greater than about 0.01 and $0.1 \mathrm{~Hz}$ at water depth of 4000 and $1000 \mathrm{~m}$, respectively). However, in the case of low frequency (e.g., $0.001 \mathrm{~Hz}$ ) and the shallow water region (e.g., $1000 \mathrm{~m}$ ), the GIE amplitude can reach $15-30 \%$ of the land cases. The second case study comes from 2-D forward simulation, and suggests that the amplitude of GIE near the coastline becomes several times larger than that of the homogeneous earth without the sea layer. The land zone with amplification has a width of about $20 \mathrm{~km}$ from the coast. Finally, using the 3-D earth's model including the complicated land-ocean distribution and bathymetry, we examined the coastal effect on GIE at the frequency of $0.001 \mathrm{~Hz}$. The amplitude of land GIE near the bay area is about ten times larger than the inland value. In addition, the seafloor GIE near the peninsula area is about four times larger than that of the other area with same water depth. These phenomena can be explained by the boundary charge along the coastal area and the concentration of electric current near the coastline.

For assessment of GIC, I conclude that 3-D earth's conductivity structure including the realistic bathymetry and the underground conductivity structure is essential and should be used. Although the simple model employing the 1-D earth's structure will be valid in the middle of continental crust and the middle in ocean, both electric fields along and across the coastline are distorted by conductivity heterogeneity. As shown here, the coastal effects on GIE is complicated and strongly depends on the water depth of ocean, crustal conductivity structure (both land and ocean), and the shape of coastline. Fortunately, efforts of electromagnetic observations and data analysis provide us a global surface conductance (conductivity-thickness product) map, 3-D regional/local conductivity models (as in a review by Thomson et al. 2009, and the compiled global model by Alekseev et al. 2015). Recent advances of seafloor electromagnetic observations also show us 3-D conductivity structure below the seafloor (e.g., upper mantle structure below the Philippine Sea and the western margin of the Pacific Ocean presented by Tada et al. 2014). Note that the observed GIE is strongly distorted even at the very low frequency by small-scale and near-surface heterogeneities of conductivity distribution (e.g., Fujii et al. 2015). Since the distortion 
on the seafloor is smaller than one on the land (Püthe et al. 2014), heterogeneous geological structure near the land surface beneath the target (e.g., power lines) should be carefully included in the local/regional 3-D conductivity model, based on boreholes and geophysical explorations (seismic surveys, magnetotellurics, and so on). In addition, electric field at the seafloor due to a 2-D or 3-D ionospheric electric current, which is a source of GIE, was partly examined (Pirjola et al. 2000; Pirjola 2002). Numerical studies with 3-D conductivity structures with 3-D ionospheric current system will be achieved in near future and very helpful for assessing the GIC hazard.

\section{Acknowledgements}

The author is grateful to Dr. Shigeru Fujita, the Meteorological College, Japan, who gave me an opportunity and hints of this study. Discussion with Dr. Takafumi Kasaya, Japan Agency for Marine-Earth Science and Technology, about the 2-D coastal effects was quite fruitful for this study. Dr. Ikuko Fujii, the Meteorological College, Japan, and two anonymous reviewers greatly improved the manuscript. This study is partly supported by Grant-in-Aid for Scientific Research (No. 26289347) funded from the Ministry of Education, Culture, Sports, Science \& Technology in Japan.

Received: 15 January 2015 Accepted: 10 November 2015

Published online: 02 December 2015

\section{References}

Alekseev D, Kuvshinov A, Palshin N (2015) Compilation of 3D global conductivity model of the Earth for space weather applications. Earth Planets Space 67: 108. doi:10.1186/s40623-015-0272-5

Baba K, Utada H, Goto TN, Kasaya T, Shimizu H, Tada N (2010) Electrical conductivity imaging of the Philippine Sea upper mantle using seafloor magnetotelluric data. Phys Earth Planet In 183(1):44-62

Bolduc L (2002) GIC observations and studies in the Hydro-Québec power system. J Atmos Sol Terr Phys 64(16):1793-1802

Boteler DH (2014) The evolution of Quebec Earth models used in modelling geomagnetically induced currents. IEEE Trans Power Delivery 99:1-8. doi:10. 1109/TPWRD.2014.2379260

Boteler DH, Pirjola RJ (2003) Magnetic and electric fields produced in the sea during geomagnetic disturbances. Pure Appl Geophys 160(9):1695-1716

Chave AD, Jones AG (2012) The magnetotelluric method: theory and practice. Cambridge University Press, Cambridge

Fujii I, Ookawa T, Nagamachi S, Owada T (2015) The characteristics of geoelectric fields at Kakioka, Kanoya, and Memambetsu inferred from voltage measurements during 2000 to 2011. Earth Planets Space 67:62. doi:10.1186/ s40623-015-0241-z

Kasaya T, Goto TN, Mikada H, Baba K, Suyehiro K, Utada H (2005) Resistivity image of the Philippine Sea plate around the 1944 Tonankai earthquake zone deduced by Marine and Land MT surveys. Earth Planets Space 57(3):209-213

Kaufman AA, Keller GV (1981) The magnetotelluric sounding method. Method in Geochemistry and Geophysics, vol. 15. Elsevier Scientific, New York, pp 595

Mackie RL, Smith JT, Madden TR (1994) Three-dimensional electromagnetic modeling using finite difference equations: The magnetotelluric example. Radio Sci 29(4):923-935

Mareschal M (1986) Modelling of natural sources of magnetospheric origin in the interpretation of regional induction studies: a review. Surv Geophys 8(3):261-300

Pirjola RJ (2002) Modelling the electric field at the seafloor due to a non-uniform ionospheric current. J Appl Geophys 49(1):3-16

Pirjola R (2005) Effects of space weather on high-latitude ground systems. Adv Space Res 36(12):2231-2240

Pirjola R (2012) Geomagnetically induced currents as ground effects of space weather. Space Science. Mosquera Cuesta HJ (ed). ISBN: 978-953-51-0423-0, InTech.

Pirjola RJ, Viljanen AT, Boteler DH (2000) Electric field at the seafloor due to a two-dimensional ionospheric current. Geophys J Int 140(2):286-294
Pulkkinen A, Kataoka R, Watari S, Ichiki M (2010) Modeling geomagnetically induced currents in Hokkaido, Japan. Adv Space Res 46(9):1087-1093. doi:10. 1016/j.asr.2010.05.024

Püthe C, Manoj C, Kuvshinov A (2014) Reproducing electric field observations during magnetic storms by means of rigorous 3-D modelling and distortion matrix co-estimation. Earth Planets Space 66: 162. doi:10.1186/s40623-014-0162-2

Rodi WL (1976) A technique for improving the accuracy of finite element solutions for magnetotelluric data. Geophys J Int 44(2):483-506

Tada N, Baba K, Utada H (2014) Three-dimensional inversion of seafloor magnetotelluric data collected in the Philippine Sea and the western margin of the northwest Pacific Ocean. Geochem Geophys Geosyst 15(7):2895-2917

Thomson AW, McKay AJ, Viljanen A (2009) A review of progress in modelling of induced geoelectric and geomagnetic fields with special regard to induced currents. Acta Geophys 57(1):209-219

Tsurutani BT, Gonzalez WD, Lakhina GS, Alex S (2003) The extreme magnetic storm of 1-2 September 1859. J Geophys Res 108(A7):1268. doi:10.1029/ 2002JA00950

Uchida T, Ogawa Y (1993) Development of Fortran code for two-dimensional magnetotelluric inversion with smoothness constraint, Geological Survey of Japan Open-File Report, No. 205

Vozoff K (1972) The magnetotelluric method in the exploration of sedimentary basins. Geophysics 37(1):98-141

Wannamaker PE, Hohmann GW, Ward SH (1984) Magnetotelluric responses of three-dimensional bodies in layered earths. Geophysics 49(9):1517-1533

Watari S (2015) Estimation of geomagnetically induced currents based on the measurement data of a transformer in a Japanese power network and geoelectric field observations. Earth Planets Space 67:77. doi:10. 1186/s40623-015-0253-8

Wei LH, Homeier N, Gannon JL (2013) Surface electric fields for North America during historical geomagnetic storms. Space Weather 11(8):451-462. doi:10. 1002/swe.20073

\section{Submit your manuscript to a SpringerOpen ${ }^{\odot}$ journal and benefit from:}

- Convenient online submission

- Rigorous peer review

- Immediate publication on acceptance

- Open access: articles freely available online

- High visibility within the field

- Retaining the copyright to your article

Submit your next manuscript at $\downarrow$ springeropen.com 